\title{
Accuracy of Rain Forecasts for Use in Scheduling Late Blight Management Tactics in the Columbia Basin of Washington and Oregon
}

\author{
Dennis A. Johnson and Thomas F. Cummings, Department of Plant Pathology, Washington State University, Pullman 99164-6430; and
} Alan D. Fox, Fox Weather LLC, Fortuna, CA 95540

\begin{abstract}
Johnson, D. A., Cummings, T. F., and Fox, A. D. 2015. Accuracy of rain forecasts for use in scheduling late blight management tactics in the Columbia Basin of Washington and Oregon. Plant Dis. 99:683-690.

Accuracy of prediction was analyzed for 17- and 30-day rain forecasts at two locations in the Columbia Basin to determine whether forecasts were sufficiently accurate to be included as a model component to schedule fungicide applications for potato late blight. Accuracy was partitioned into specificity (percentage of forecasted nonrainfall events classified correctly) and sensitivity (percentage of forecasted daily rainfall events classified correctly). An adjusted sensitivity, which included the forecasted rain day plus the next 2 days, was also used to give a wider target than only 1 day for evaluating accuracy of forecasted rain events. For 17day forecasts, specificity during the seasonal test period was $\geq 70 \%$ from mid-June through September and specificity over the days of the forecast was $>70 \%$ for the first 8 days at both locations both years. Adjusted sensitivity over days of the forecast was initially $>80 \%$ and then decreased as forecasts increased from 7 to 17 days for 17-day forecasts at both

locations and years. Sensitivity and adjusted sensitivity during the seasonal test period were both positively correlated with the number of rainy days while specificity was negatively correlated. Adjusted sensitivity was considerably higher for May (month with highest incidence of rain) than July (month with lowest incidence of rain) at both locations. For 30day forecasts, specificity during the test period was $>75 \%$ in July and August and adjusted sensitivity ranged from 60 to $100 \%$ for time periods occurring in May and June during both sample seasons. Specificity was generally above $80 \%$ as days of the forecast increased and adjusted sensitivity varied greatly over days of the forecasts, with extremes between 0 and $100 \%$ at both locations and years for the 30-day forecasts. Specificity of 17- and 30-day rain forecasts and adjusted sensitivity of 17-day rain forecasts have utility in scheduling late blight fungicides in the Columbia Basin.
\end{abstract}

The Columbia Basin of south-central Washington and north-central Oregon is a major potato-growing region in North America. Potato crops are grown on more than 80,000 ha in the region annually, with mean tuber yields approximating $74 \mathrm{t} / \mathrm{ha}$ in 2012 . The region is isolated and bordered by mountains. Potato crops are mainly planted in March through April and harvested from August through October. The environment is semiarid and the potato crop is irrigated mostly by center-pivot systems. The potato canopy after foliar closure between rows provides a favorable environment for late blight development when fields are sprinkler irrigated. Even though potato fields are irrigated with approximately 50 to $76 \mathrm{~cm} /$ ha for a growing season, an increase in the number or rainy days increases the favorability for late blight development and spread of late blight inoculum within fields and to adjacent and nearby potato crops $(1,20)$.

Phytophthora infestans, the cause of potato late blight disease, is capable of destroying potato crops in 2 to 3 weeks during diseasefavoring weather when disease control tactics are not applied (14). Rain and mild temperatures favor the disease $(2,13,26)$. Disease management is dependent on eliminating sources of initial infection, irrigation management in irrigated regions, mechanically forming adequate hills of soil over developing tubers, and fungicides $(12,22,23,30,33)$.

Fungicides are most effective when applied just before wet environmental conditions favoring infection. Predictive models are used to schedule fungicide applications in several potato-growing regions of North America, Mexico, and Europe (2,7,25,28,30,34). Models developed in rain-fed agricultural regions that are based on leaf wetness or relative humidity and temperature in individual fields such as BLITECAST have not effectively scheduled fungicides applications for control of late blight in the semiarid Columbia Basin and southern Idaho $(6,10)$.

Corresponding author: D. A. Johnson, E-mail: dajohn@wsu.edu

Accepted for publication 14 October 2014.

http://dx.doi.org/10.1094/PDIS-06-14-0602-RE

(C) 2015 The American Phytopathological Society
Two sets of forecasting models for each of four locations are used to regionally forecast the probability of late blight occurrence for the Columbia Basin. The first set of models estimates the probability of late blight occurrence early in the growing season and the second estimates the probability of disease occurrence in midseason $(15,17)$. The models were derived using logistic regression by examining the relationship of late blight occurrence in the region with meteorological variables over 27 years at Prosser, North Richland, and Othello, WA and Hermiston, OR. Separate logistic regression models were derived for the early and midseasons for each of the four vicinities. Indicator variables for the early-season logistic models include the presence of an outbreak during the preceding year and number of rainy days in April and May. Indicator variables for the midseason models include the presence of an outbreak the preceding year and either number of rainy days in July and August or number of rainy days in April and May plus number of rainy days in July and August, depending on the vicinity. Variation in number of rainy days in the spring occurs among the four vicinities, and having more than one location or vicinity has been beneficial in making reliable disease forecasts (15).

The late blight models had high sensitivity (percentage of years with late blight outbreaks classified correctly) and specificity (percentage of years without outbreaks classified correctly) when validated. As with predictive models used for foliar diseases, a high sensitivity is desired for the models used in the Basin. All years with late blight outbreaks in 26 of 27 (96\%) years of data used to develop the logistic models were correctly classified using data from at least one of the four locations (15). All 18 years since the late blight models were first developed in 1997 through 2014 have been correctly classified at each of the four vicinities.

The probability of late blight occurrence for a given season can be calculated on 1 June when the number of rainy days in April and May is known. However, the probabilities can be estimated in early May from the actual number of rainy days in April and a 30-day rain forecast for May. This is currently done and a late blight forecast is usually given in early May. Early May is several weeks before row closure and sufficient time for growers to implement late blight management tactics. The advanced knowledge is beneficial because 
fungicides used for late blight are mostly protective and, to achieve the maximum effect, the first application must be made before $P$. infestans becomes established on foliage of the crop (11). In addition, sufficient time and applications are also needed for fungicides to be adequately distributed throughout the plant canopy after the initial application, especially if the application is made by air.

In replicated trials in northern Idaho, fungicides applied to 'Ranger Russet' potato prior to rainy weather was as effective as a 7-day application schedule in controlling late blight at half the number of fungicide applications. A 14-day application schedule reduced late blight severity compared with the nontreated control but did not satisfactorily control the disease (nonpublished data). Fungicide applied after rainy days are not effective in preventing infection. Coupling rain forecasts with late blight forecasting models to schedule fungicide applications may improve late blight management in the Columbia Basin. However, the accuracy of rain forecast needs to be sufficiently high to add value in scheduling fungicide applications. Weather forecasts are available from various sources. Development of potato late

Table 1. Number of days forecasted with rain days, specificity, sensitivity, and adjusted sensitivity for weekly sets of combined five consecutive 17-day forecasts at Prosser and Othello, WA in $2010^{\mathrm{a}}$

\begin{tabular}{|c|c|c|c|c|c|c|c|c|c|c|c|}
\hline \multirow[b]{2}{*}{ Range of days } & \multirow[b]{2}{*}{$N^{\mathbf{b}}$} & \multicolumn{5}{|c|}{ Prosser } & \multicolumn{5}{|c|}{ Othello } \\
\hline & & Pred $^{c}$ & Rain $^{\mathrm{c}}$ & Spec $^{d}$ & Sens $^{e}$ & Adj sens ${ }^{f}$ & Pred $^{c}$ & Rain $^{\mathrm{c}}$ & Spec $^{d}$ & Sens $^{e}$ & Adj sens ${ }^{f}$ \\
\hline 10-30 May & 85 & 44 & 28 & $51(7)$ & $57(9)$ & $79(8)$ & 44 & 22 & $46(6)$ & $45(11)$ & $95(4)$ \\
\hline 17 May-6 June & 85 & 42 & 36 & $55(7)$ & $56(8)$ & $67(8)$ & 37 & 31 & $67(6)$ & $61(9)$ & $61(9)$ \\
\hline 21 May-16 June & 85 & 30 & 40 & $84(5)$ & $58(8)$ & $60(8)$ & 31 & 35 & $78(6)$ & $57(8)$ & $69(8)$ \\
\hline 31 May-20 June & 85 & 23 & 29 & $77(6)$ & $34(9)$ & $38(9)$ & 29 & 28 & $68(6)$ & $39(9)$ & $61(9)$ \\
\hline 7-27 June & 85 & 12 & 15 & $90(4)$ & $33(12)$ & $33(12)$ & 19 & 15 & $80(5)$ & $33(12)$ & 47 (13) \\
\hline 14 June-4 July & 85 & 27 & 13 & $68(5)$ & $31(13)$ & $85(10)$ & 28 & 13 & $71(5)$ & $54(14)$ & $85(10)$ \\
\hline 21 June-11 July & 85 & 13 & 5 & $85(4)$ & $20(18)$ & $80(18)$ & 23 & 5 & $75(5)$ & $60(22)$ & 100 \\
\hline 28 June-18 July & 85 & 11 & 10 & 89 (4) & $30(14)$ & $30(14)$ & 18 & 9 & $76(5)$ & 0 & $33(16)$ \\
\hline 5-25 July & 85 & 1 & 5 & 99 (1) & 0 & 0 & 5 & 5 & $94(3)$ & 0 & 0 \\
\hline 12 July-1 August & 85 & 12 & 8 & $87(4)$ & $25(15)$ & $13(12)$ & 20 & 12 & $78(5)$ & $33(14)$ & $25(13)$ \\
\hline 19 July-8 August & 85 & 12 & 10 & $84(4)$ & 0 & $60(15)$ & 15 & 15 & $86(4)$ & $33(12)$ & 100 \\
\hline 23 July-15 August & 85 & 13 & 10 & 87 (4) & $30(14)$ & $60(15)$ & 12 & 13 & $93(3)$ & $54(14)$ & $69(13)$ \\
\hline 2-22 August & 85 & 7 & 0 & $92(3)$ & ud & ud & 8 & 0 & $91(3)$ & ud & ud \\
\hline 9-29 August & 85 & 9 & 0 & $89(3)$ & ud & ud & 11 & 0 & $87(4)$ & ud & ud \\
\hline 16 August-5 September & 85 & 0 & 5 & 100 & 0 & 0 & 1 & 5 & $99(1)$ & 0 & 0 \\
\hline 23 August-12 September & 85 & 12 & 13 & $88(4)$ & $23(12)$ & $46(14)$ & 15 & 9 & $86(4)$ & $44(17)$ & 100 \\
\hline 30 August-19 September & 85 & 16 & 27 & $83(5)$ & $22(8)$ & $44(10)$ & 21 & 14 & $75(5)$ & $21(11)$ & $86(9)$ \\
\hline 6-26 September & 85 & 27 & 41 & $70(7)$ & $34(7)$ & $54(8)$ & 30 & 22 & $70(6)$ & $50(11)$ & $86(7)$ \\
\hline
\end{tabular}

a Abbreviation: ud $=$ undefined, rain predicted within forecast but no actual rain event (number of successful days predicted $/ 0$ rain $=0 / 0$ ).

b Number of days.

${ }^{\mathrm{c}}$ Pred $=$ number of days $(n=85)$ that rain was predicted and Rain $=$ days with actual rain from set of five consecutive weekly 18 day forecasts.

${ }^{\mathrm{d}}$ Specificity = percentage of correctly predicted days without rain/days without rain (standard error of mean).

e Sensitivity = percentage of correctly predicted days with rain/days with rain (standard error of mean).

${ }^{\mathrm{f}}$ Adjusted sensitivity $=15$-day sensitivity derived from 17-day forecast of correctly predicted days with rain on days of prediction or the following 2 days/days of rain (standard error of mean).

Table 2. Number of days forecasted with rain days, specificity, sensitivity, and adjusted sensitivity for weekly sets of combined five consecutive days of 17-day forecasts at Prosser and Othello, WA in 2011

\begin{tabular}{|c|c|c|c|c|c|c|c|c|c|c|c|}
\hline \multirow[b]{2}{*}{ Range of days } & \multirow[b]{2}{*}{$N^{\mathbf{b}}$} & \multicolumn{5}{|c|}{ Prosser } & \multicolumn{5}{|c|}{ Othello } \\
\hline & & Pred $^{c}$ & Rain $^{c}$ & Spec $^{d}$ & Sens ${ }^{\mathrm{e}}$ & $\overline{\operatorname{Adj}_{\text {sens }}}{ }^{\mathrm{f}}$ & Pred $^{c}$ & Rain $^{\mathrm{c}}$ & Spec $^{d}$ & Sens $^{\mathrm{e}}$ & $\overline{\text { Adj sens }^{f}}$ \\
\hline 10-30 May & 85 & 47 & 22 & $44(6)$ & $55(11)$ & $82(8)$ & 47 & 30 & $44(7)$ & $53(9)$ & $60(9)$ \\
\hline 17 May-6 June & 85 & 38 & 24 & $56(6)$ & $46(10)$ & 100 & 36 & 29 & $63(6)$ & $52(9)$ & $86(6)$ \\
\hline 21 May-16 June & 85 & 48 & 28 & $46(7)$ & $61(9)$ & 100 & 48 & 37 & $46(7)$ & $59(8)$ & 100 \\
\hline 31 May-20 June & 85 & 31 & 13 & $68(5)$ & $62(13)$ & 100 & 28 & 16 & $70(6)$ & $44(12)$ & 100 \\
\hline 7-27 June & 85 & 19 & 8 & $79(5)$ & $38(17)$ & $75(15)$ & 15 & 9 & $84(4)$ & $33(16)$ & 78 (14) \\
\hline 14 June-4 July & 85 & 27 & 5 & $73(5)$ & 100 & 100 & 26 & 8 & $68(5)$ & $13(12)$ & 100 \\
\hline 21 June-11 July & 85 & 20 & 0 & $76(5)$ & ud & $\mathrm{Ud}$ & 23 & 6 & $72(5)$ & $17(15)$ & 100 \\
\hline 28 June-18 July & 85 & 19 & 0 & $78(5)$ & ud & $\mathrm{Ud}$ & 15 & 10 & $84(4)$ & $30(14)$ & $90(9)$ \\
\hline 5-25 July & 85 & 17 & 0 & $80(4)$ & ud & $\mathrm{Ud}$ & 17 & 9 & $80(5)$ & $22(14)$ & $22(14)$ \\
\hline 12 July-1 August & 85 & 15 & 5 & $81(4)$ & 0 & 0 & 23 & 13 & $74(5)$ & $31(13)$ & $54(14)$ \\
\hline 19 July-8 August & 85 & 10 & 5 & $89(4)$ & $20(18)$ & $20(18)$ & 8 & 9 & $95(3)$ & $44(17)$ & $56(17)$ \\
\hline 23 July-15 August & 85 & 6 & 1 & $93(3)$ & 0 & 0 & 10 & 10 & $88(4)$ & $10(9)$ & $20(13)$ \\
\hline 2-22 August & 85 & 2 & 0 & $98(2)$ & ud & $\mathrm{Ud}$ & 5 & 10 & $93(3)$ & 0 & 0 \\
\hline 9-29 August & 85 & 12 & 0 & $86(4)$ & ud & $\mathrm{Ud}$ & 16 & 11 & $81(5)$ & $18(12)$ & $36(15)$ \\
\hline 16 August-5 September & 85 & 4 & 0 & $95(2)$ & ud & $\mathrm{Ud}$ & 6 & 5 & $93(3)$ & 0 & 0 \\
\hline 23 August-12 September & 85 & 8 & 0 & $91(3)$ & ud & $\mathrm{Ud}$ & 16 & 4 & $80(4)$ & 0 & 0 \\
\hline 30 August-19 September & 85 & 12 & 0 & $86(4)$ & ud & $\mathrm{Ud}$ & 20 & 2 & $76(5)$ & 0 & $50(35)$ \\
\hline
\end{tabular}

a Abbreviation: ud = undefined, rain predicted within forecast but no actual rain event (number of successful days predicted/0 rain $=0 / 0$ ).

b Number of days.

${ }^{c}$ Pred $=$ number of days $(n=85)$ that rain was predicted and Rain $=$ days with actual rain from set of five consecutive weekly 17-day forecasts.

${ }^{\mathrm{d}}$ Specificity = percentage of correctly predicted days without rain/days without rain (standard error of mean).

e Sensitivity = percentage of correctly predicted days with rain/days with rain (standard error of mean).

f Adjusted sensitivity = 15-day sensitivity derived from 17-day forecast of correctly predicted days with rain on days of prediction or the following 2 days/days of rain (standard error of mean). 
blight is weather dependent $(2,7,10,11,15,17,19,20,26,32)$, and the goal of this study was to evaluate rain forecasts for accuracy, which could be used to schedule fungicide applications for managing potato late blight. The disease control strategy desired is to forecast and prevent future infection periods versus forecasting disease symptoms after infection periods (24).

\section{Materials and Methods}

Rain forecasts for two locations in the Columbia Basin of Washington were provided by Fox Weather, LLC, Fortuna, CA in 2010 and 2011. Forecasts were generated for points near the cities of Othello and Prosser, WA. Othello is approximately $88 \mathrm{~km}$ northnortheast of Prosser. The rain forecast consisted of $24 \mathrm{~h}$ of total liquid precipitation (rainfall). Only measurable rainfall in amounts $\geq 0.25 \mathrm{~mm}$ were forecasted. Original forecasts consisted of 17 - and 30-day predictions.

The 17-day rain forecasts were based on the Global Forecast System model results and were hand generated by forecasting meteorologist Zane A. Stephens. The primary inputs for timing, probability, and amount of precipitation were adjusted subjectively by the forecaster. The 30-day forecasts were calculated using different models. Contributing models included the Madden Julian Oscillation, PacificNorth American cycle, Arctic Oscillation, and current and projected (within 1 month) pattern of sea-surface temperature anomalies using methods developed by Fox Weather as adapted from Namias (29). The rain-cycle peak and length of period in days were determined subjectively from the cycles that were dominant at the time.

The 17-day forecasts were issued 5 days a week (Monday through Friday) from 5 May to 14 September 2010 (Table 1) and 2 May to 31 August 2011 (Table 2). Number of forecasts produced for each location was 93 in 2010 and 88 in 2011. The 30-day forecasts for rain were obtained weekly from 16 May to 9 September 2010 and 10 May to 1 September 2011 (Table 3). Numbers of forecasts produced for each location were 14 in 2010 and 15 in 2011. The time period of the rain forecasts, which will hereafter be referred to as the test period, began approximately 3 to 5 weeks before foliar closure between rows to fall harvest and covered the time that late blight may visually increase and spread in potato crops in the Columbia Basin.

Actual amounts of rainfall were obtained for the same two locations and time periods as the rain forecasts. Rain data were collected using automatic CR-1000 data loggers (Campbell Scientific, Logan UT) operated by Washington State University (AgWeatherNet, Prosser, WA) or Oregon State University (Hermiston Agricultural Research and Extension Center, Hermiston, OR) near each location. Data sets were created with actual and predicted precipitation matched by year, date, and location. Predicted and actual rainfalls were analyzed as binary events of either day with or without rain.

Accuracy was partitioned into specificity and sensitivity, where specificity is the percentage of forecasted nonrainfall events classified correctly and sensitivity is the percentage of forecasted daily rainfall events classified correctly. Therefore, specificity was calculated as: (rain event not forecasted and not observed/[rain event forecasted but not observed + rain event not forecasted and not observed]) $\times 100$. Sensitivity was calculated as (rain event forecasted and observed/[rain event forecasted and observed + rain event not forecasted but observed]) $\times 100$ (34). Adjusted sensitivity was used to give a wider target than only 1 day for evaluating accuracy of forecasted rain events and included the forecasted day for rain plus the next 2 days. Hence, adjusted sensitivity was derived from the number of forecasted daily rainfall events that were within any consecutive

Table 3. Mean of predicted (Pred) and actual number of days with rainfall relative to single 30-day rain forecasts for Prosser and Othello, WA in 2010 and 2011

\begin{tabular}{|c|c|c|c|c|c|c|c|c|c|}
\hline \multicolumn{5}{|c|}{2010} & \multicolumn{5}{|c|}{2011} \\
\hline \multirow[b]{2}{*}{ Forecast range } & \multicolumn{2}{|c|}{ Prosser } & \multicolumn{2}{|c|}{ Othello } & \multirow[b]{2}{*}{ Forecast range } & \multicolumn{2}{|c|}{ Prosser } & \multicolumn{2}{|c|}{ Othello } \\
\hline & Pred & Actual & Pred & Actual & & Pred & Actual & Pred & Actual \\
\hline 16 May-15 Jun & 9 & 12 & 9 & 10 & 10 May-8 Jun & 8 & 9 & 8 & 12 \\
\hline 1-30 Jun & 10 & 8 & 10 & 7 & 17 May-15 Jun & 10 & 6 & 8 & 8 \\
\hline 10 Jun-Jul9 & 6 & 3 & 7 & 3 & 24 May-22 Jun & 16 & 7 & 17 & 9 \\
\hline 15 Jun-Jul14 & 6 & 4 & 6 & 4 & 30 May-28 Jun & 6 & 4 & 6 & 5 \\
\hline 18 Jun-Jul17 & 6 & 4 & 6 & 3 & 8 Jun-7 Jul & 6 & 2 & 6 & 3 \\
\hline 1-31 Jul & 2 & 3 & 5 & 4 & 13 Jun-12 Jul & 4 & 1 & 5 & 2 \\
\hline 13 Jul-11 Aug & 3 & 3 & 5 & 4 & 20 Jun-19 Jul & 6 & 0 & 8 & 3 \\
\hline 19 Jul-17 Aug & 5 & 2 & 5 & 3 & $1-30 \mathrm{Jul}$ & 2 & 1 & 4 & 4 \\
\hline 1-31 Aug & 4 & 0 & 3 & 0 & $12 \mathrm{Jul}-10 \mathrm{Aug}$ & 6 & 1 & 8 & 4 \\
\hline 3 Aug-Sep2 & 3 & 1 & 3 & 1 & $20 \mathrm{Jul}-18 \mathrm{Aug}$ & 3 & 1 & 4 & 4 \\
\hline 9 Aug-Sep8 & 6 & 1 & 6 & 1 & $28 \mathrm{Jul}-26 \mathrm{Aug}$ & 3 & 0 & 4 & 3 \\
\hline 17 Aug-Sep15 & 0 & 4 & 1 & 2 & 10 Aug-8 Sep & 4 & 0 & 4 & 3 \\
\hline 26 Aug-Sep24 & 6 & 10 & 9 & 6 & 16 Aug-14 Sep & 4 & 0 & 6 & 1 \\
\hline \multirow[t]{2}{*}{$6 \mathrm{Sep}-5 \mathrm{Oct}$} & 9 & 9 & 11 & 5 & 24 Aug-22 Sep & 3 & 0 & 3 & 4 \\
\hline & & & & & 1-30 Sep & 3 & 0 & 3 & 4 \\
\hline
\end{tabular}
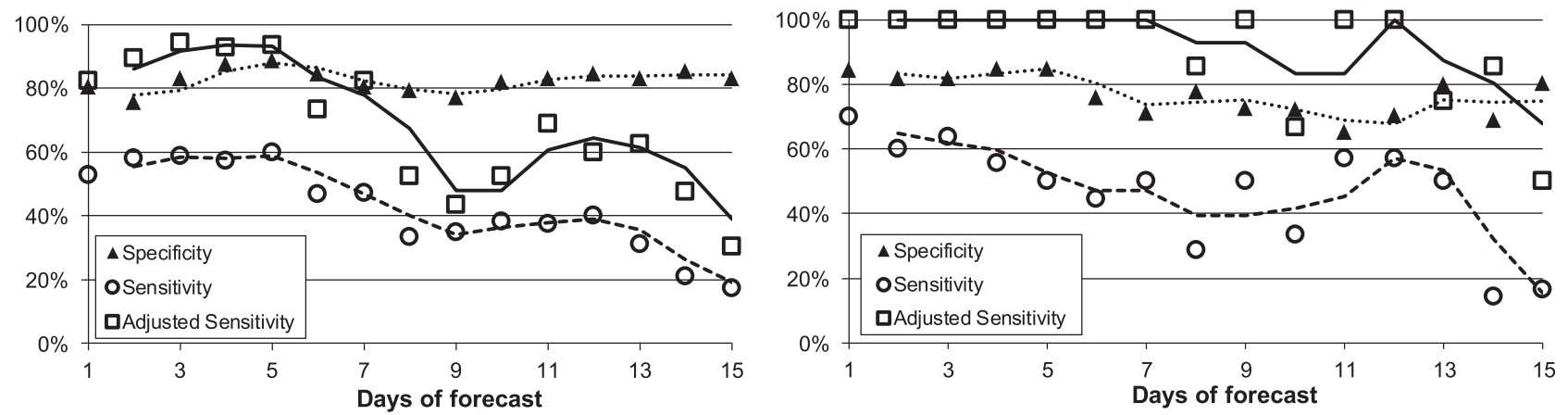

Fig. 1. Mean specificity, mean sensitivity, and mean adjusted sensitivity for 17-day rain forecasts over days of the forecasts at Prosser, WA in 2010 (left) and 2011 (right). Fifteen days were reported because consecutive 3-day clusters were used to calculate adjusted sensitivity. 
3 days that had an actual rain event and divided by number of actual rain events. The maximum value for adjusted sensitivity was set at $100 \%$ to correspond to the concept of sensitivity and to treat the 3 days as one unit. The rationale for the 3 -day target was that a fungicide applied just before the first day would be effective in managing late blight throughout the 3-day period. A fungicide applied after rainfall would not be effective in managing late blight.

Sensitivity was determined as ' 0 ' when there was actual rain within forecasts but no prediction was successful on a day of rain or for adjusted sensitivity within 2 days of a rain event. Sensitivity and adjusted sensitivity were undefined when rain was predicted but there was no actual rain within the predicted forecast (number of days predicted $/ 0$ rain $=$ undefined).

False-positive and false-negative rain predictions were calculated. False positive was determined as (rain event forecasted but not observed/[rain event forecasted and observed + rain event forecasted but not observed] $) \times 100$. False negative was determined as (rain event not forecasted but was observed/[rain event not forecasted and not observed + rain event not forecasted but was observed] $\times 100(34)$. The false-positive and false-negative statistics have a negative orientation; therefore, the smaller values are preferred.

The five daily consecutive 17-day rain forecasts of a given week $(n=85)$ were analyzed collectively, giving a reported mean accuracy for each given week, and will hereafter be termed the weekly set of forecasts. Thus, the number of weekly sets of forecasts that were analyzed was 18 and 17 in 2010 and 2011, respectively, which provided integrated intervals of accuracy throughout the test period. The 30-day forecasts were not combined and were analyzed singly for accuracy. In addition, analysis for accuracy was also done by daily
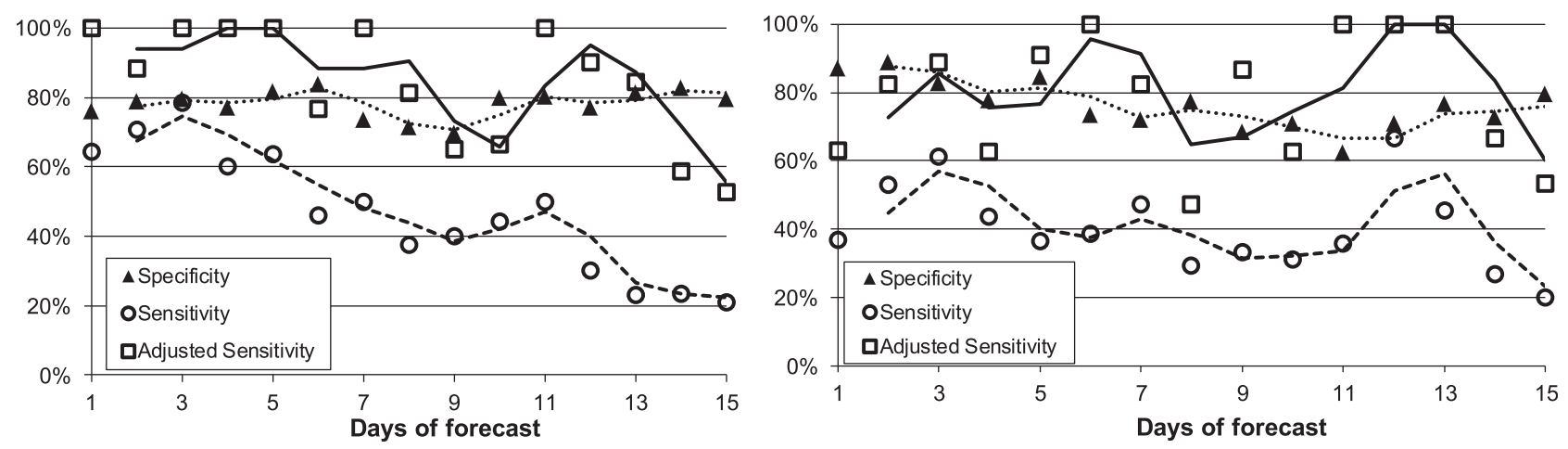

Fig. 2. Mean specificity, mean sensitivity, and mean adjusted sensitivity for 17-day rain forecasts over days of the forecasts at Othello, WA in 2010 (left) and 2011 (right). Fifteen days were reported because consecutive 3-day clusters were used to calculate adjusted sensitivity.
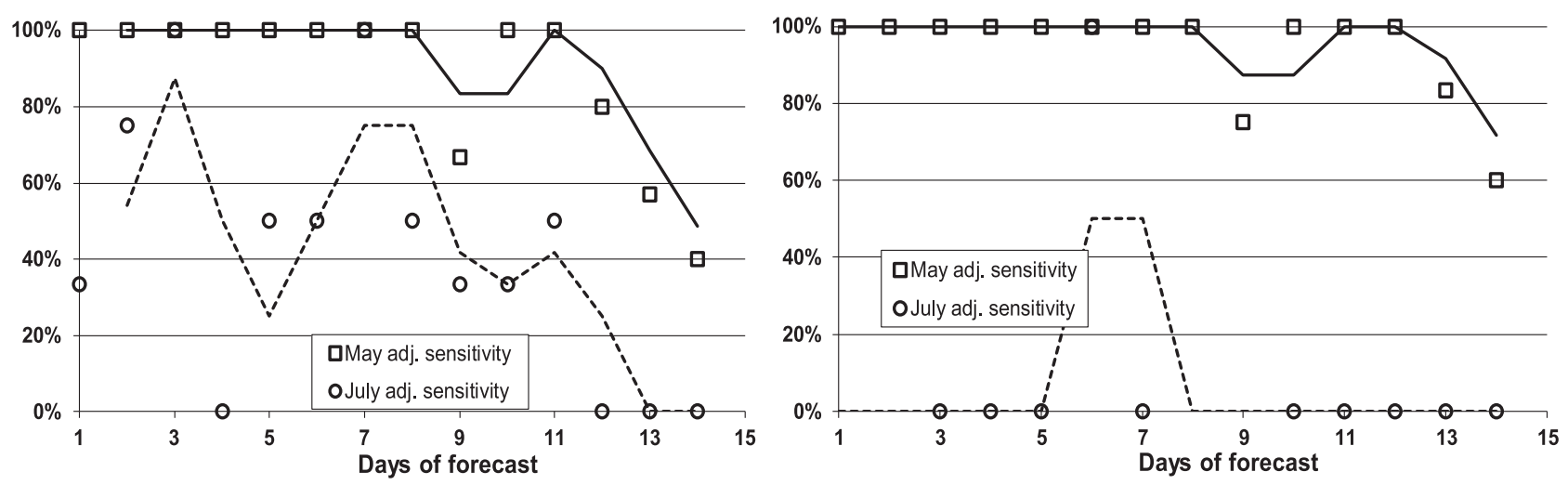

Fig. 3. Mean adjusted sensitivity for 17-day rain forecasts over days of the forecasts in May and July at Prosser, WA in 2010 (left) and 2011 (right). Fifteen days were reported because consecutive 3-day clusters were used to calculate adjusted sensitivity.
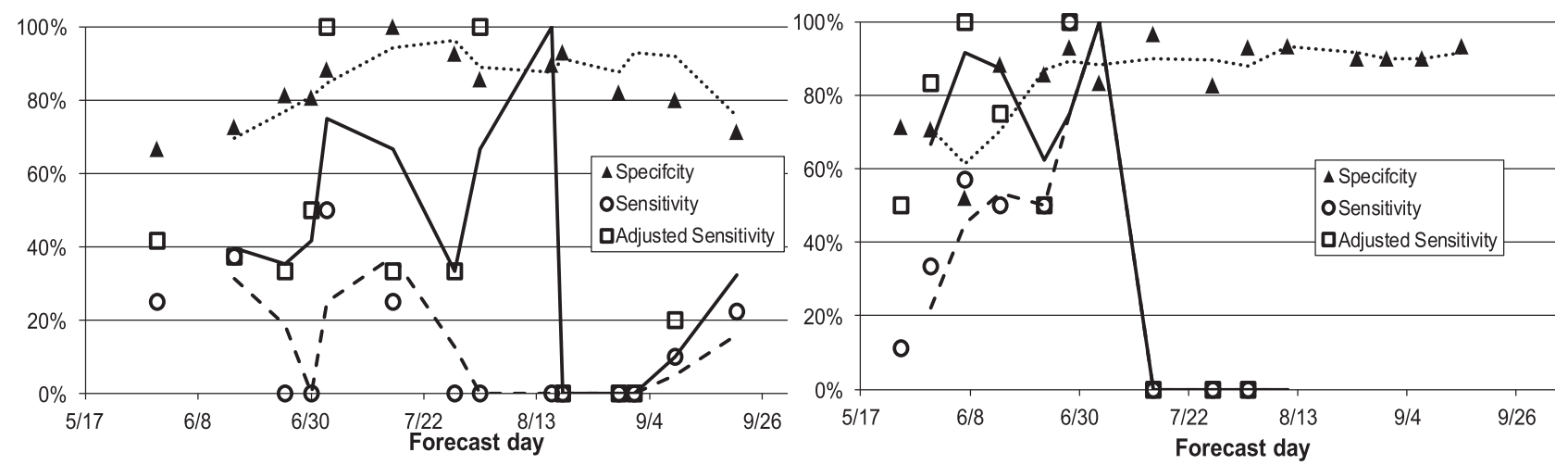

Fig. 4. Mean specificity, mean sensitivity and mean adjusted sensitivity for 30-day rain forecasts over the test season at Prosser, WA in 2010 (left) and 2011 (right) (lines are 2-day moving average). 
increment along the time series of forecast days (days of forecast) so that each day from the first predicted day of a forecast through the end of the 17- or 30-day forecasts was given a mean value for specificity, sensitivity, and adjusted sensitivity. Mean values for each day of forecast were taken from combined forecasts for location-year for the test period.

The total number of days of the forecasts for deriving adjusted sensitivity was minus 2 days from either the 17 or 30 days of the original forecasts because the variable required consecutive 3-day clusters to calculate. Thus, the number of days for which adjusted sensitivity is reported was 15 and 28 for the original 17- and 30-day forecasts, respectively. Sensitivity and specificity are also reported to 15 and 28 days for the two respective lengths of rain forecasts.

\section{Results}

Actual number of days with rain varied between Prosser and Othello in 2010 and 2011. The number of days in which rain was forecasted usually exceeded the actual number of days with rain for all locations and for both the 17- and 30-day rain forecasts (Tables 1, 2, and 3).

Specificity during the test period was generally greater than $70 \%$ for the 17-day rain forecasts at Prosser and Othello in 2010 and 2011 (Tables 1 and 2). Specificity during the test periods was higher in June, July, and August than in May at both locations in both years (Tables 1 and 2).

Sensitivity and adjusted sensitivity during the test period for the 17-day rain forecasts varied within locations and years. Mean sensitivity was $\geq 60 \%$ for 4 of 58 weekly sets of forecasts and adjusted sensitivity was $\geq 60 \%$ for 32 of 58 weekly sets of forecasts at Prosser and Othello for both years, excluding periods when no rain occurred and sensitivity was undefined (Tables 1 and 2). Specificity over days of forecast was generally above $75 \%$ for the 17-day forecasts at both locations in both years (Figs. 1 and 2). Adjusted sensitivity was initially above $80 \%$ and then decreased as days of forecast increased from 7 to 15 days for the 17-day forecasts at Prosser in 2010 and 2011 (Fig. 1). The same trends occurred at Othello in

Table 4. Mean, standard error of mean (in parentheses), and range for measures of accuracy for 17-day rain forecasts over the test season at two locations and 2 years

\begin{tabular}{lccccc}
\hline & \multicolumn{2}{c}{$\mathbf{2 0 1 0}(\boldsymbol{\%})$} & & \multicolumn{2}{c}{$\mathbf{2 0 1 1}(\%)$} \\
\cline { 2 - 3 } \cline { 6 - 6 } Accuracy $^{\mathbf{a}}$ & Prosser & Othello & & Prosser & Othello \\
\hline Specificity $^{\mathrm{b}}$ & $82(4)$ & $79(5)$ & & $78(4)$ & $76(5)$ \\
Range & $51-100$ & $46-99$ & & $44-98$ & $44-95$ \\
Sensitivity & $28(9)$ & $37(10)$ & & $42(9)$ & $25(9)$ \\
Range & $0-58$ & $0-61$ & & $0-100$ & $0-59$ \\
Adj. sensitivity & $47(10)$ & $64(7)$ & & $64(5)$ & $56(9)$ \\
Range & $0-85$ & $0-100$ & & $0-100$ & $0-100$ \\
False positive & $74(8)$ & $76(7)$ & & $91(3)$ & $83(6)$ \\
Range & $23-100$ & $35-100$ & & $71-100$ & $50-100$ \\
Adj. false positive & $52(10)$ & $56(8)$ & & $81(4)$ & $62(8)$ \\
Range & $4-100$ & $14-100$ & & $23-100$ & $14-100$ \\
False negative & $17(4)$ & $14(4)$ & & $7(2)$ & $14(4)$ \\
Range & $0-47$ & $0-30$ & & $0-0$ & $0-41$ \\
\hline
\end{tabular}

a Values based over five daily consecutive 17-day rain forecasts for a given week $(n=85)$ for 18 and 17 weeks in 2010 and 2011, respectively, for each location.

b Specificity = percentage of correctly predicted days without rain by days without rain.

c Sensitivity $=$ percentage of correctly predicted days with rain by days with rain.

d Adjusted (Adj.) sensitivity = 15-day sensitivity derived from 17-day forecast of correctly predicted days with rain on days of prediction or the following 2 days by days of rain.

e False positive $=$ percentage of predicted rain days not observed by total of all predicted rain days or for adjusted includes day of prediction with the following 2 days.

${ }^{\mathrm{f}}$ False negative $=$ percentage of nonpredicted rain days not observed by total of all nonpredicted rain days.
2010 but were more erratic in 2011 (Fig. 2). Mean sensitivity for 17-day forecasts from the first 5 days of prediction to the last 5 days was reduced by a half to a third at Prosser during both years (Fig. 1).

Adjusted sensitivity over days of forecast for the 17-day forecasts was compared between the month having the highest number of days with rain (May) and the month having the lowest number of days with rain (July). Adjusted sensitivity was considerably higher for May than July at both locations. As an example, data for both years at Prosser are illustrated in Figure 3. Adjusted sensitivity was 100\% for at least the first 7 days of the May rain forecasts at Prosser each year (Fig. 3).

For the 17-day rain forecasts, mean false positives or the mean percentages of incorrect predicted rainfall events for the test season were 74 to $91 \%$ and mean adjusted false positives were lower, at 52 to $81 \%$, at the two locations and years (Table 4). Mean false negatives or the mean percentages of incorrect predicted nonrainfall events were 7 to $17 \%$ for the two locations and years (Table 4). Mean false positives for the days of the forecasts were 64 to $82 \%$ and mean adjusted false positives were 42 to $62 \%$ at the two locations and years (Table 5). Mean false negatives were 6 to $15 \%$ for the two locations and years (Table 5).

Specificity, sensitivity, and adjusted sensitivity each varied during the test period for the 30-day forecasts at Prosser and Othello in 2010 and 2011. Specificity during the test periods was generally above $80 \%$ after the end of June at both locations during both years. Sensitivity during the test period was mostly below 0.50 at both locations both years. (Figs. 4 and 5). Adjusted sensitivity at both locations ranged from 60 to $100 \%$ for time periods occurring in May and June during both sample seasons (Figs. 4 and 5).

Mean specificity was generally above $80 \%$ as days of forecast increased for the 30-day forecasts at both locations both years (Figs. 6 and 7). Mean sensitivity over days of forecast decreased to near zero after day 4 of the forecast but peaked higher at various times during the 30-day forecast at Prosser and Othello both years. Adjusted sensitivity varied greatly among days of the forecasts and peaked at $100 \%$ several times at Prosser and Othello both years (Figs. 6 and 7).

Table 5. Mean, standard error of mean (in parentheses), and range for measures of accuracy for days of the forecast for 17-day rain forecasts at two locations and 2 years

\begin{tabular}{lllllc}
\hline & \multicolumn{2}{c}{ 2010(\%) } & & \multicolumn{2}{c}{ 2011 (\%) } \\
\cline { 2 - 3 } \cline { 5 - 6 } Mean accuracies $^{\text {a }}$ & Prosser & Othello & & Prosser & Othello \\
\hline Specificity $^{\mathrm{b}}$ & $83(4)$ & $78(5)$ & & $78(5)$ & $76(95)$ \\
Range & $77-88$ & $70-84$ & & $65-85$ & $62-89$ \\
Sensitivity & $41(11)$ & $45(12)$ & & $46(17)$ & $39(12)$ \\
Range & $17-60$ & $21-79$ & & $14-70$ & $8-67$ \\
Adj. sensitivity & $68(10)$ & $84(6)$ & & $91(5)$ & $79(8)$ \\
Range & $30-94$ & $53-100$ & & $50-100$ & $47-100$ \\
False positive & $64(11)$ & $72(9)$ & & $82(8)$ & $75(9)$ \\
Range & $50-75$ & $57-86$ & & $63-96$ & $47-94$ \\
Adj. false positive & $42(11)$ & $49(10)$ & & $62(10)$ & $48(10)$ \\
Range & $22-58$ & $39-59$ & & $37-82$ & $18-69$ \\
False negative & $15(4)$ & $12(4)$ & & $6(3)$ & $14(4)$ \\
Range & $8-25$ & $5-20$ & & $4-10$ & $5-18$ \\
\hline
\end{tabular}

a Values for combined days (1 to 17) within 93 forecasts in 2010 and 88 in 2011.

b Specificity = percentage of correctly predicted days without rain by days without rain

c Sensitivity $=$ percentage of correctly predicted days with rain by days with rain.

d Adjusted (Adj.) sensitivity = 15-day sensitivity derived from 17-day forecast of correctly predicted days with rain on days of prediction or the following 2 days by days of rain.

e False positive $=$ percentage of predicted rain days not observed by total of all predicted rain days or for adjusted includes day of prediction with the following 2 days.

${ }^{\mathrm{f}}$ False negative $=$ percentage of nonpredicted rain days not observed by total of all nonpredicted rain days or for adjusted includes day of prediction with the following 2 days. 
Mean false positives \pm standard error for the 30-day forecasts ranged were $86 \pm 9 \%$ at Prosser in 2010, $88 \pm 9 \%$ at Othello in 2010, $91 \pm 6 \%$ at Prosser in 2011 and $87+8 \%$ at Othello in 2011. Mean false negatives were $16 \pm 7 \%$ at Prosser in 2010, $14 \pm 6 \%$ at Othello in 2010, $6 \pm 3 \%$ at Prosser in 2011 and $15+7 \%$ at Othello in 2011 .

\section{Discussion}

The Columbia Basin is in a rain shadow of the Cascade Mountain Range due to prevailing winds from the southwest and west. Consequently, accurately forecasting when rain will occur is more difficult than accurately forecasting when rain will not occur. In agreement, specificity for the 17- and 30-day rain forecast was relatively high, generally above $80 \%$ for both over the test period and for the days of the forecasts. Knowing when rain is not going to occur can be helpful in making late blight management decisions. This can be advantageous during expected "dry periods", such as July, to lengthen intervals between fungicide applications.
Sensitivity was variable and often below $50 \%$ over the test period and after day 6 for days of forecast. Adjusted sensitivity for days of forecast was higher than sensitivity, as expected, and was above $80 \%$ for at least the first 6 days of the forecasts for the 17-day forecasts. Adjusted sensitivity was sufficiently high to be valuable in making late blight management decisions. A target window wider than 1 day improved forecast sensitivity. A late blight fungicide applied just before the beginning of the 3-day window would provide protection for the entire period.

Sensitivity of 30-day rain forecasts was especially limited during dry seasonal periods and was attenuated further within a forecast as day from initiation progressed. For example, sensitivity over days of a forecast (day 1 to day 30 ) had a sharp reduction of accuracy after the first 15 days of a forecast and was erratic. The mean for days of forecast correctly predicting a rain event was $31.3 \%$ for the first 15 days and $9.8 \%$ for the last 13 days over the 2010 and 2011 test seasons at Prosser and Othello. Nevertheless, sensitivity of the

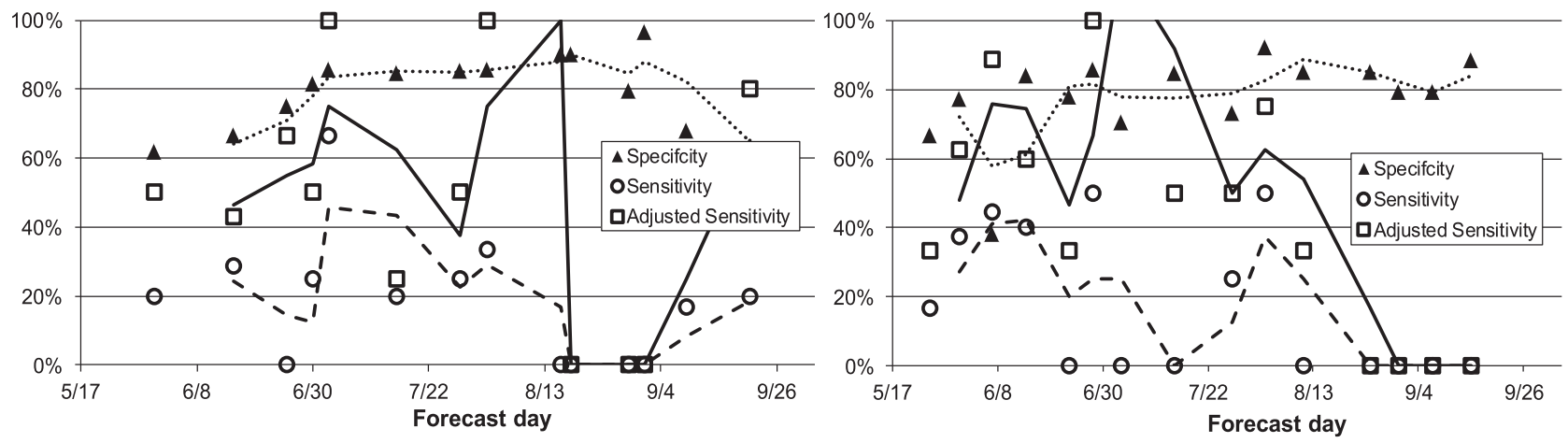

Fig. 5. Mean specificity, mean sensitivity, and mean adjusted sensitivity for 30-day rain forecasts over the test season at Othello, WA in 2010 (left) and 2011 (right) (lines are 2-day moving average).
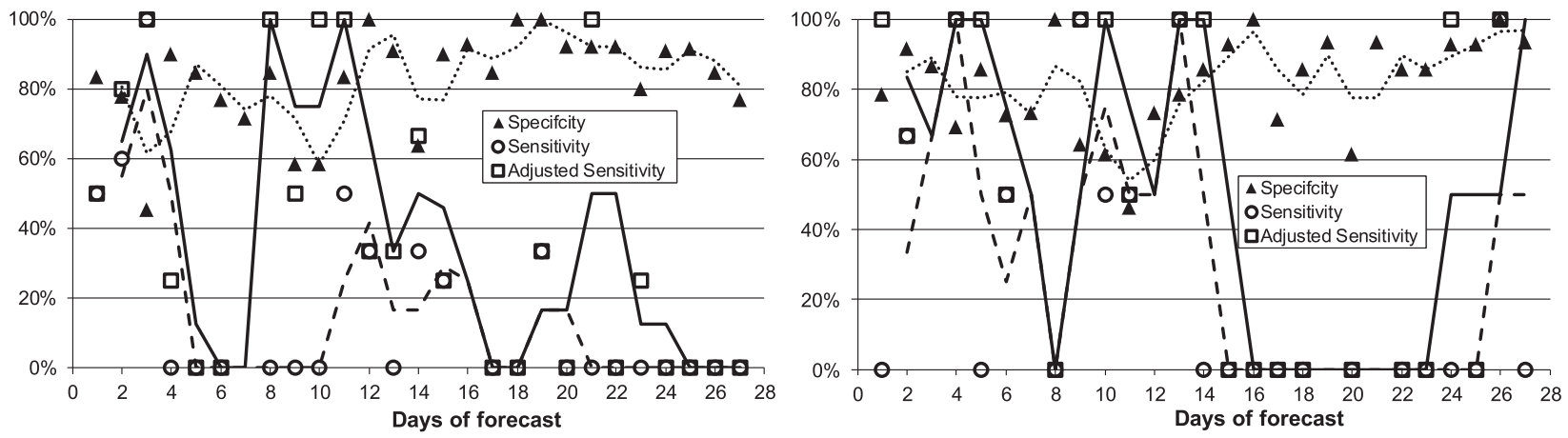

Fig. 6. Mean specificity, mean sensitivity and mean adjusted sensitivity for 30-day rain forecasts over days of the forecast at Prosser, WA in 2010 (left) and 2011 (right).
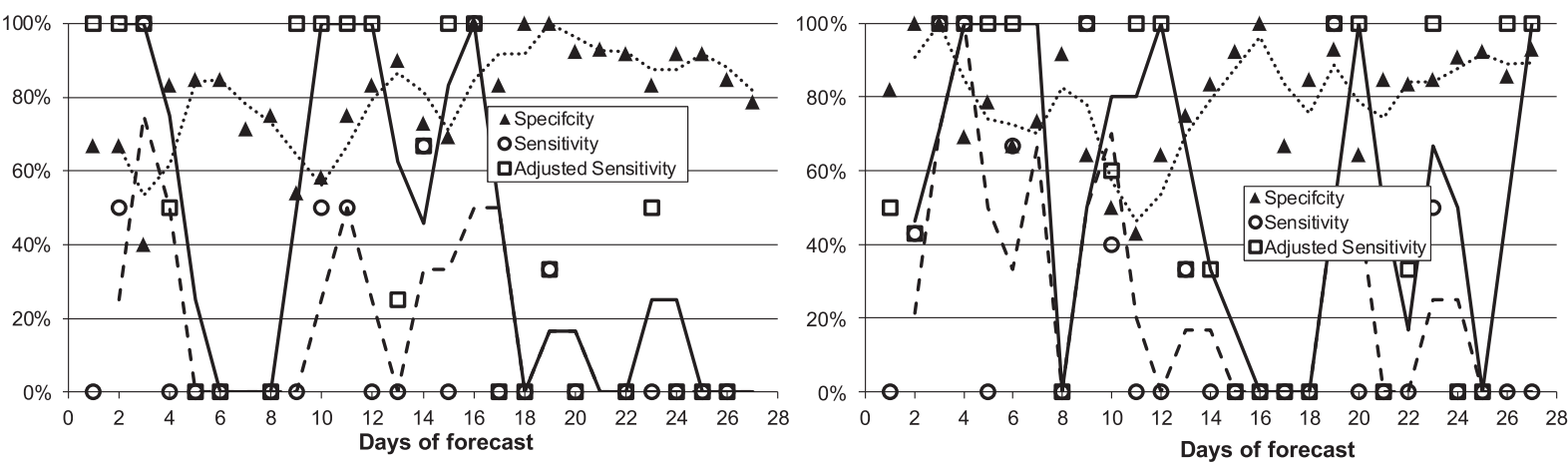

Fig. 7. Mean specificity, mean sensitivity, and mean adjusted sensitivity for 30-day rain forecasts over days of the forecast at Othello, WA in 2010 (left) and 2011 (right). 
weekly sets of forecasts was often above 50\% during the wetter months of May and June and for the forecast for both the 17- and 30-day rain forecasts during the wetter months. Sensitivity could be valuable in predicting rainy days during this time. Adjusted sensitivity was again higher than sensitivity for the 30-day rain forecast but also greatly varied over the test season and the days of the forecasts. Because sensitivity and adjusted sensitivity decreased as days of the forecast increased, rain forecasts should be monitored daily when used for late blight management. An adequate time of at least 2 to 3 days to schedule and make a fungicide application from the day of the forecast was usually available before an actual rainy day during the test periods in the current study.

A reason for using adjusted sensitivity as a measure of precipitation occurrence is that air masses in the prevailing westerly flow over the Columbia Basin during the growing season are dry. In dry air masses, more than one band of showers may be required to sufficiently moisten the air mass to allow rain to reach the ground. Subsequent bands insert more moisture into an air mass and increase the probability of measurable rain at a station. Also, predicting the timing of rain within a day more than 8 days in advance is difficult for weather prediction models.

Rainfall sometimes occurs for more than 1 day in the Columbia Basin. However, two or more consecutive days of rain were found not to be a reliable predictor whereas individual rainy days were a reliable predictor of incidence of late blight in the Columbia Basin in a previous study (19). Adjusted sensitivity in the current study applied to both individual and consecutive rainy days, when they occurred. Fungicide application may need to be applied before a cluster of rainy days and during the cluster (if of sufficient duration). Presence of inoculum and other factors would also be important considerations $(14,32)$.

Specificity and sensitivity are both important parameters for disease prediction models $(14,15)$. A high sensitivity or adjusted sensitivity is desired for potato late blight so that future rainy periods are identified and potential infections prevented with fungicide. A "missed" fungicide application could lead to increased late blight, with associated losses and management costs in the field and tuber storage $(16,21)$. A high specificity allows a reduction of fungicide use when dry weather is expected.

Reliability of 30-day rain forecasts has not been satisfactory in the past $(3,4)$. The low sensitivities and adjusted sensitivities after days 4 and 5 for the 30-day forecasts in the current study were related to the weak and intermittent characteristic of the westerlies during test periods. The seasonably diminished strength of the westerlies and their occasional interruption by other patterns make it difficult to estimate the length of quasiperiodic variations in flow that are usually observed during other seasons. Such interruptions are often caused by monsoonal flow of moisture and rains from the southwestern U.S. deserts, or subtropical high pressure that extends into Washington State during the summer. Sometimes, bursts in the westerlies can be anticipated, which can produce an occasional forecast for rain 18 to 25 days out that agrees well with the observations. However, with currently used techniques, a consistent occurrence would not have been expected. The first 15 days of the 30-day rain forecasts did not always agree with the 15-day rain forecasts because different atmospheric models and methods were used for the two types of predictions.

The high values for false positives in the current study are due to overpredicting rainfall events during seasonal periods characterized by infrequent rain occurrences $(5,35)$. Overpredicting is preferred to underpredicting rainfall for late blight management so as not to miss infection periods induced by rain. A more appropriate measurement for a false positive under these climatological conditions may be the probability of false detection, which includes the correct predicted no-rain element and can be derived from Tables 1 and 2 by subtracting specificity from $100 \%$ (5). Therefore, sensitivity and specificity being based on ratios of total occurrences or nonoccurrences, respectively, achieve together a suitable description of rainfall events in the Columbia Basin.

Rain forecasts could be helpful in scheduling fungicide applications for late blight management in the Columbia Basin. Management would be directed at preventing infection versus forecasting disease symptoms (24). However, fungicide applications for late blight management in the Columbia Basin should not rely solely on targeting fungicide applications before rain. Growth stage of the crop, abundance and location of late blight inoculum in the region, and method of application are important factors. Fungicide seed treatments reduce spread from infected seed tubers during cutting, handling, and planting $(12,13,18,27,31)$. Concerning growth stage, late blight has not been detected before row closure in commercial fields in the Columbia Basin and late blight fungicides are not usually needed before this growth stage. However, two fungicide applications are needed when applied by air to adequately distributed fungicide for good protection throughout the crop canopy after row closure $(8,9)$. In addition, fungicide protection may be needed to restrict transmission of $P$. infestans from infected seed tubers to shoots in the field during major rainy periods before or during row closure $(13,19,22)$. Fungicide applications should be continued until harvest if late blight is present in a field or neighboring fields. Periods with dew, especially when juxtaposed with wet periods from irrigation water, favor infection and dictate fungicide protection of foliage.

Early-season rain in April and May is an effective indicator of late blight outbreaks because moisture is important for the build-up of inoculum in fields during the early stage of epidemics. Early in epidemics, moisture promotes transmission of $P$. infestans from infected seed tubers and infected volunteer tubers to emerged shoots in fields. Transmission from infected tubers to shoots bearing sporangia can occur within $24 \mathrm{~h}$ during rainy weather (13). Secondary infections will proceed almost immediately if a favorable environment with moisture continues. Moisture is also essential for effective dissemination of sporangia to additional fields.

In summary, specificity of 17-day and 30-day rain forecasts and adjusted sensitivity of 17-day rain forecasts have utility in scheduling late blight fungicides in the semiarid environment of the Columbia Basin. The rain forecasts could be used to help schedule fungicide applications and to predict indicator variables (number of rainy days in April and May and in July and August) for the early and midseason late blight forecasting models (15). Actual number of rainy days in April and forecasted rainy days in May could be used for the early season late blight models and actual number of rainy days in July and forecasted rainy days in August could be used for the midseason late blight models. A rain forecast that was targeted 1 to 2 days before the actual day of rain is valuable for disease management in that a fungicide could be applied before the wet period so that infection could be prevented.

\section{Acknowledgments}

This research was partially funded by an AFRI grant. We thank R. A. Alldredge, C Thomas, and D. Gent for critical presubmission reviews of the manuscript.

\section{Literature Cited}

1. Aylor, D. E., Fry, W. E., Mayton, H., and Andrade-Piedra, J. L. 2001. Quantifying the rate of release and escape of Phytophthora infestans sporangia from a potato canopy. Phytopathology 91:1189-1196.

2. Beaumont, A. 1947. The dependence on the weather of the dates of outbreaks of potato late blight epidemics. Trans. Br. Mycol. Soc. 31:45-53.

3. Coakley, S. M. 1983. Ambient meteorological factors-light, temperature, and moisture. Pages 154-167 in: Challenging Problems in Plant Health. T. Kommedahol and P. M. Williams, eds. American Phytopathological Society, St. Paul, MN.

4. Coakley, S. M. 1988. Variation in climate and prediction of disease in plants. Annu. Rev. Phytopathol. 26:163-181.

5. Doswell, C. A., III, Davies-Jones, R., and Keller, D. L. 1990. On summary measures of skill in rare event forecasting based on contingency tables. Weather Forecast. 5:576-585.

6. Easton, G. D. 1982. Late blight of potatoes and prediction of epidemics in arid central Washington State. Plant Dis. 66:452-455.

7. Grunwald, N. J., Rubio-Covarrubias, O., and Fry, W. E. 2000. Potato late blight management in the Toluca Valley: Forecasts and resistant cultivars. Plant Dis. 84:410-416.

8. Hamm, P. B., and Clough, G. H. 1999. Comparison of application methods on deposition and redistribution of chlorothalonil in a potato canopy and potential for control of late blight. Plant Dis. 83:441-444.

9. Hamm, P. B., Cummings, T. F., and Johnson, D. A. 2006. Comparison of deposition patterns in two programs for applying protectant fungicides to 
potato stems and leaves for the control of late blight (Phytophthora infestans). Am. J. Potato Res. 83:473-484.

10. Henderson, D., Williams, C. J., and Miller, J. S. 2007. Forecasting late blight in potato crops of southern Idaho using logistic regression analysis. Plant Dis. 91:951-956.

11. Hirst, J. M., and Stedman, O. J. 1960. The epidemiology of Phytophthora infestans II. The source of inoculum. Ann. Appl. Biol. 48:489-517.

12. Inglis, D. A., Powelson, M. L., and Dorrance, A. E. 1999. Effect of registered potato seed piece fungicides on tuber-borne Phytophthora infestans. Plant Dis. 83:229-234.

13. Johnson, D. A. 2010. Transmission of Phytophthora infestans from infected potato seed tubers to emerged shoots. Plant Dis. 94:18-23.

14. Johnson, D. A., Alldredge, J. R., and Allen, J. R. 1994. Weather and downy mildew epidemics of hop in Washington State. Phytopathology 84:524-527.

15. Johnson, D. A., Alldredge, J. R., and Hamm, P. B. 1998. Expansion of potato late blight forecasting models for the Columbia Basin of Washington and Oregon. Plant Dis. 82:642-645.

16. Johnson, D. A., Alldredge, J. R., Hamm, P. B., and Frazier, B. E. 2003. Aerial photography used for spatial pattern analysis of late blight infection in irrigated potato circles. Phytopathology 93:805-812.

17. Johnson, D. A., Alldredge, J. R., and Vakoch, D. L. 1996. Potato late blight forecasting models for the semiarid environment of south-central Washington. Phytopathology 86:480-484.

18. Johnson, D. A., and Cummings, T. F. 2009. Latent infection of potato seed tubers by Phytophthora infestans during long term cold storage. Plant Dis. 93:940-946.

19. Johnson, D. A., and Cummings, T. F. 2013. A plant stem inoculation assay for assessing transmission of Phytophthora infestans from potato seed tubers to emerged shoots. Plant Dis. 97:183-188.

20. Johnson, D. A., Cummings, T. F., Abi Ghanem, R., and Alldredge, J. R. 2009. Association of solar irradiance and days of precipitation with incidence of potato late blight in the semiarid environment of the Columbia Basin. Plant Dis. 93:272-280.

21. Johnson, D. A., Cummings, T. F., and Hamm, P. B. 2000. Cost of fungicides used to manage potato late blight in the Columbia Basin: 1996 to 1998. Plant Dis. 84:399-402.
22. Johnson, D. A., Hamm, P. B., Miller, J. S., and Porter, L. D. 2012. Late blight epidemics in the Columbia Basin. Pages 141-162 in: Sustainable Potato Production: Global Case Studies. Z. He, R. Larkin, and W. Honeycutt, eds. Springer, New York.

23. Johnson, D. A., Inglis, D. A., and Miller, J. S. 2004. Control of potato tuber rots caused by oomycetes with foliar applications of phosphorous acid. Plant Dis. 88:1153-1159.

24. Krause, R. A., and Massie, L. B. 1975. Predictive systems: Modern approaches to disease control. Annu. Rev. Phytopathol. 13:31-47.

25. Krause, R. A., Massie, L. B., and Hyre, R. A. 1975. BLITECAST: A computerized forecast of potato late blight (Phytophthora infestans). Plant Dis. Rep. 59:95-98.

26. Lacey, L. 1967. The role of water in the spread of Phytophthora infestans in the potato crop. Ann. Appl. Biol. 59:245-255.

27. Lambert, D. H., Currier, A. I., and Olanya, M. O. 1998. Transmission of Phytophthora infestans in cut potato seed. Am. J. Potato Res. 75:257-263.

28. MacKenzie, D. R. 1981. Scheduling fungicide applications for potato late blight with BLITECAST. Plant Dis. 65:394-399.

29. Namias, J. 1981. Teleconnections of 700-mb height anomalies for the Northern Hemisphere. In: CALCOFI Atlas No. 29. Marine Life Research Program, Scripps Institution of Oceanography, La Jolla, CA.

30. Porter, L. D., Cummings, T. F., and Johnson, D. A. 2006. Effects of soilapplied late blight foliar fungicides on infection potato tubers by Phytophthora infestans. Plant Dis. 90:964-968.

31. Powelson, M. L., and Inglis, D. A. 1999. Foliar fungicides as protective seed piece treatments for management of late blight of potatoes. Plant Dis. 83:265-268

32. Rotem, J., Cohen, Y., and Putter, J. 1971. Relativity of limiting and optimum inoculum loads, wetting durations, and temperatures for infection by Phytophthora infestans. Phytopathology 61:275-278.

33. Stevenson, W. R., Kirk, W. W., and Atallah, Z. K. 2008. Managing foliar diseases: Early blight, late blight, and white mold. Pages 209-222 in: Potato Health Management. D. A. Johnson, ed. American Phytopathological Society, St. Paul, MN.

34. Wallin, J. R. 1962. Summary of recent progress in predicting late blight epidemics in United States and Canada. Am. Potato J. 39:306-312.

35. Wilks, D. S. 2006. Statistical Methods in the Atmospheric Sciences, 2nd ed. Academic Press, Elsevier, NY. 